\title{
GERMINAÇÃO DE SEMENTES DE Passiflora setacea E DORMÊNCIA INDUZIDA PELO ARMAZENAMENTO'
}

\author{
JULIANO GOMES PÁDUA²; LAÍSSA CASTELO SCHWINGEL³; ROSÂNGELA CALDAS MUNDIM; \\ ANTONIETA NASSIF SALOMÃO5; SOLANGE CARVALHO BARRIOS ROVERIJOSÉ 6
}

\begin{abstract}
RESUMO - Objetivou-se nesse trabalho avaliar a germinação inicial de sementes de Passiflora setacea DC com diferentes níveis de umidade e após a conservação sob diferentes temperaturas. Foram utilizados tratamentos pré-germinativos com nitrato de potássio $\left(\mathrm{KNO}_{3}\right)$ e ácido giberélico $\left(\mathrm{GA}_{3}\right)$. A germinação foi conduzida em papel germitest embebido em água. O teste de tetrazólio foi empregado para verificar a viabilidade das sementes após os períodos de armazenamento. Foi possível verificar que: (i) as sementes de $P$. setacea podem ser desidratadas até atingir, aproximadamente $4,7 \%$ de água (base úmida) sem perda da capacidade de germinação; (ii) o armazenamento de sementes com baixo teor de água, a baixas temperaturas pode induzir a dormência de sementes de P. setacea; (iii) a dormência é superada pelo tratamento das sementes com ácido giberélico, até o quinto mês de armazenamento; (iv) as sementes conservadas sob temperaturas subzero apresentaram maior porcentagem de viabilidade em relação às armazenadas a $4{ }^{\circ} \mathrm{C}$. Diante destes resultados, pode-se concluir que sementes de $P$. setacea podem ser conservadas por até 8 meses, sob baixas temperaturas, a -20 ou $-196^{\circ} \mathrm{C}$, pois mantêm os padrões mínimos de viabilidade estabelecidos internacionalmente.
\end{abstract}

Termos para indexação: maracujá do mato, viabilidade, conservação, ácido giberélico.

\section{GERMINATION OF Passiflora setacea SEEDS AND STORAGE INDUCED DORMANCY}

\begin{abstract}
The objective in this study was establish long-term conservation conditions for Passiflora setacea seeds by testing different seed moisture contents and storage temperatures. Seeds were treated with potassium nitrate $\left(\mathrm{KNO}_{3}\right)$ and gibberellic acid $\left(\mathrm{GA}^{3}\right)$ before germination in moistened paper towels. Seed viability was verified by the tetrazolium test after the seeds had been treated. It was observed that: (i) P. setacea seeds can be dried to approximately $4.7 \%$ of water content (fresh weight basis) without a significant reduction in germination, (ii) low temperatures and low water content induced dormancy in P. setacea seeds; (iii) dormancy could be overcome by seed treatment with gibberellic acid until the fifth month of storage; (iv) seeds maintained at subzero temperatures showed a higher viability compared to those stored at $4^{\circ} \mathrm{C}$. It was concluded that $P$. setacea seeds can be stored for up to eight months, at -20 or $-196{ }^{\circ} \mathrm{C}$, since they maintain the minimum international standards for viability.
\end{abstract}

Index terms: passionflower, viability, conservation, gibberelic acid.

\footnotetext{
${ }^{1}$ Submetido em 06/07/2010. Aceito para publicação em 25/10/2010.

${ }^{2}$ Eng. Agrônomo, D. Sc., Embrapa Recursos Genéticos e Biotecnologia, Caixa Postal 02372, CEP 70770-917, Brasília/DF, jgpadua@cenargen. embrapa.br

${ }^{3}$ Bióloga, Estagiária, Embrapa Recursos Genéticos e Biotecnologia, laissa@cenargen.embrapa.br
}

${ }^{4}$ Geógrafa, Embrapa Recursos Genéticos e Biotecnologiarosa@cenargen.
embrapa.br ${ }^{5}$ Eng. Florestal, M. Sc., Embrapa Recursos Genéticos e Biotecnologia, antoniet@cenargen.embrapa.br

${ }^{6}$ Eng. Agr., D. Sc., Embrapa Recursos Genéticos e Biotecnologia, solangebr@cenargen.embrapa.br 


\section{INTRODUÇÃO}

As espécies de maracujá pertencem à família Passifloraceae que é composta por dezenove gêneros, sendo Passiflora, o de maior importância (Braga e Junqueira, 2000), tanto em relação ao número de espécies ( Bernacci et al., 2003; Vitta e Bernacci, 2004) quanto do ponto de vista econômico (Oliveira et al., 1994; Souza e Meletti, 1997). A produção mundial de maracujá, no ano de 2007 foi de 664 mil toneladas, sendo o Brasil o maior produtor (Mezzalira et al., 2009), com aproximadamente 400 mil toneladas, produzidas em 47 mil hectares (IBGE, 2009).

No Brasil são encontradas cerca de 120 espécies do gênero Passiflora, sendo as regiões central e norte onde há maior ocorrência (Oliveira et al., 1994; Souza e Meletti, 1997). O maracujá-amarelo ( $P$. edulis Sims. f. flavicarpa Deg.) é a espécie mais cultivada no Brasil, no entanto, o cultivo do maracujá-doce ( $P$. alata Curtis) tem mostrado crescimento significativo (Braga et al., 2005). Recentemente, com a intensificação da coleta do germoplasma de Passiflora, tem-se dado maior atenção aos parentes silvestres do maracujá, possibilitando sua incorporação aos programas de melhoramento genético, permitindo a obtenção de híbridos interespecíficos entre espécies pouco exploradas comercialmente (Oliveira e Ruggiero, 2005), seja para a incorporação de resistência contra doenças às espécies comerciais (Junqueira et al., 2005) ou para fins ornamentais (Peixoto, 2005).

A propagação de Passiflora é feita por sementes que, de forma geral, apresentam germinação baixa e desuniforme, dificultando a formação de mudas de alta qualidade, sendo um grande problema enfrentado pelos produtores (Souza e Meletti, 1997). Dessa forma, é importante conhecer os aspectos que afetam a germinação das sementes. Dentre estes, destacam-se os de origem genética (variação entre espécies e cultivares), de pré e pós-colheita (injúrias mecânicas durante a colheita, problemas fitossanitários, variações climáticas, secagem, armazenamento), morfológicos, fisiológicos (dormência, maturidade, vigor), dentre outros.

Pouco se conhece sobre a questão da dormência de sementes, principalmente em se tratando de espécies frutíferas tropicais (Barros, 2006). Ellis et al. (1985) citam que as espécies de Passiflora apresentam sementes semipermeáveis, que permitem pronta captação de água, mas contêm inibidores de germinação. Delanoy et al. (2006) demonstraram que embriões excisados de Passiflora spp. germinam rapidamente, evidenciando a existência de dormência.

Estudos relacionados aos fatores que interferem na viabilidade e vigor são importantes para definição de procedimentos a serem adotados nos testes para a avaliação do potencial fisiológico das sementes. Esses estudos são importantes também na definição da estratégia mais adequada para o armazenamento, principalmente em espécies não cultivadas, em que a heterogeneidade genética e fisiológica das amostras é acentuada. Assim, esta pesquisa teve como objetivos avaliar a germinação de sementes de Passiflora setacea em resposta a diferentes níveis de desidratação, exposição a baixas temperaturas e a tratamentos pré-germinativos, visando gerar conhecimentos para subsidiar o estabelecimento de procedimentos para a conservação de suas sementes a longo prazo.

\section{MATERIAL E MÉTODOS}

As sementes de Passiflora setacea foram obtidas de frutos maduros, com retirada manual do arilo. As sementes foram mantidas durante sete dias sob temperatura ambiente; em seguida, foi realizada a determinação do grau de umidade (base úmida) pelo método da estufa a 105 ${ }^{\circ} \mathrm{C} \pm 2{ }^{\circ} \mathrm{C}$, por 24 horas (Brasil, 1992). As sementes foram separadas em lotes aleatórios e acondicionadas em caixas de plástico hermeticamente fechadas, em temperatura ambiente, contendo sílica gel, na proporção aproximada de $5 \mathrm{~g}$ de sílica para cada $1 \mathrm{~g}$ de semente. A cada 24 horas, durante cinco dias, as sementes foram retiradas daquelas caixas e acondicionadas em novas caixas, também hermeticamente fechadas, sem sílica gel, obtence-se dessa forma, 5 lotes distintos quanto ao grau de umidade. De cada caixa, foram retiradas três amostras de dez sementes para determinação do grau de umidade das mesmas. Uma amostra inicial (testemunha), com quatro repetições de 25 sementes, foi submetida a testes de germinação em papel toalha umedecido com quantidade de água equivalente a 2,5 vezes o peso do papel. Adicionalmente, testes de germinação foram realizados utilizando-se tratamento (imersão por 24 horas) com promotores de germinação: nitrato de potássio $\left(\mathrm{KNO}_{3}\right)$ e ácido giberélico $\left(\mathrm{GA}_{3}\right)$, nas concentrações de $0,2 \%$ pv e $1 \mathrm{mM}$, respectivamente. Os rolos de papel foram colocados em germinador com temperatura alternada $\left(25 / 30{ }^{\circ} \mathrm{C}\right)$ e fotoperíodo de 16 horas. Outro experimento foi conduzido para verificar o efeito do conteúdo de água das sementes e da temperatura 
de armazenamento sobre a manutenção da viabilidade das sementes de $P$. setacea. Assim, de cada lote anteriormente obtido, com teores de água distintos, foram retiradas três amostras (700 sementes) para armazenamento a $4{ }^{\circ} \mathrm{C},-20$ ${ }^{\circ} \mathrm{C}$ e $-196{ }^{\circ} \mathrm{C}$. Essas sementes foram acondicionadas em 5 sacos aluminizados (cada um contendo 140 sementes), ou em tubos criogênicos (contendo 140 sementes), no caso de armazenamento em nitrogênio líquido (NL) a $-196{ }^{\circ} \mathrm{C}$. Mensalmente, foi retirado um recipiente e as sementes nele contidas submetidas a testes de germinação, conforme descrito anteriormente, com quatro repetições de 25 sementes cada. Ao final do experimento foi calculada a porcentagem de sementes germinadas, considerando-se a protrusão da raiz primária como critério para determinar a germinação.

Adicionalmente, foram conduzidos testes de tetrazólio para avaliação da viabilidade das sementes armazenadas, com 2 repetições de 20 sementes cada, por tratamento, pré-condicionadas em água por 24 horas a $30{ }^{\circ} \mathrm{C}$. A seguir procedeu-se ao corte na extremidade distal do eixo embrionário e, em seguida, as sementes permaneceram embebidas em solução de cloreto de trifenil tetrazólio $0,75 \%$ a $30{ }^{\circ} \mathrm{C}$, por 24 horas. Para a avaliação da viabilidade, os embriões foram excisados e visualizados sob lupa, sendo considerados viáveis aqueles que apresentaram coloração rósea em pelo menos metade do cotilédone e de todo o eixo embrionário.

Assim, no caso do primeiro experimento, no qual foi avaliado o efeito do grau de umidade e dos tratamentos pré-germinativos com $\mathrm{GA}_{3}$ e $\mathrm{KNO}_{3}$, foi utilizado o delineamento inteiramente casualizado, em esquema fatorial ( 5 x 3), com quatro repetições, cada uma contendo 25 sementes. Para o experimento destinado à avaliação do efeito da temperatura de armazenamento foi utilizado o delineamento inteiramente casualizado, com três tratamentos (três temperaturas). Cada tratamento foi representado por quatro repetições de 25 sementes. Os dados de germinação foram transformados, utilizando-se a função arco-seno, de forma a permitir a realização das análises de variância e, as médias, comparadas pelo teste de Tukey $(\mathrm{p} \leq 0,05)$.

\section{RESULTADOS E DISCUSSÃO}

Após a retirada das sementes do fruto e do seu processamento (retirada do arilo), as sementes apresentavam grau de umidade médio de 16,9\% (base úmida). Pode-se verificar que as sementes de $P$. setacea toleram a desidratação até $4,7 \%$ de água, sem perdas significativas de germinação (PG). A maior redução do grau de umidade comprometeu a viabilidade das sementes. Como se observa na Tabela 1 , sementes com 3,7\% de água apresentaram germinação inferior à dos demais tratamentos. Para todos os teores de água avaliados, não houve diferença significativa entre os $\mathrm{PG}$ dos lotes submetidos ao tratamento com $\mathrm{GA}_{3}$.

TABELA 1. Porcentagem de germinação de sementes de $P$. setacea com diferentes graus de umidade (peso fresco), tratadas com $\mathrm{KNO}_{3}$ e $\mathrm{GA}_{3}$.

\begin{tabular}{cccc}
\hline $\begin{array}{c}\text { Grau de Umidade } \\
\text { Inicial }(\%)\end{array}$ & $\begin{array}{c}\text { Testemunha } \\
(\%)\end{array}$ & $\begin{array}{c}\mathrm{KNO}_{3} \\
(\%)\end{array}$ & $\begin{array}{c}\mathrm{GA}_{3} \\
(\%)\end{array}$ \\
\hline 16,9 & $80 \mathrm{Aa}$ & $100 \mathrm{Aa}$ & $100 \mathrm{Aa}$ \\
10,2 & $100 \mathrm{Aa}$ & $97 \mathrm{Aa}$ & $100 \mathrm{Aa}$ \\
9,2 & $100 \mathrm{Aa}$ & $98 \mathrm{Aa}$ & $96 \mathrm{Aa}$ \\
4,7 & $96 \mathrm{Aa}$ & $96 \mathrm{Aa}$ & $94 \mathrm{Aa}$ \\
3,7 & $68 \mathrm{Bb}$ & $72 \mathrm{Bb}$ & $88 \mathrm{Aa}$ \\
\hline
\end{tabular}

Médias seguidas pela mesma letra minúscula na linha, e maiúscula na coluna, não diferem estatisticamente (Teste Tukey, $\mathrm{p} \leq 0,05$ ).

De acordo com os dados obtidos, é possível verificar que o baixo grau de umidade das sementes e a baixa temperatura de armazenamento atuaram de forma a induzir a dormência em sementes de $P$. setacea (Tabela 2). De forma geral, as condições de armazenamento sob baixas temperaturas em sementes com teor de água reduzido podem promover a superação de dormência, há alguns exemplos na literatura que mostram que estas mesmas condições apresentam efeito oposto, ou seja, induzem dormência (Ruiz et al., 1999; Wood et al., 2000; Pritchard, 2004; Albrecht e Mccarthy, 2007; PérezGarcía et al., 2007). Na presente pesquisa, a desidratação por si só não se mostrou como fator indutor da dormência, pois não foi detectada diferença significativa entre as porcentagens de germinação de sementes com diferentes teores de água, compreendidos entre 16,9\% e 4,7\%. Dessa forma, possivelmente, a indução de dormência tenha sido causada pela temperatura ou, mais provavelmente, pela interação dos fatores temperatura, umidade e período de armazenamento. Assim, é preciso que novas pesquisas sejam realizadas para determinar a influência de cada um destes fatores na viabilidade de sementes de $P$. setacea. 
TABELA 2. Porcentagem de germinação (PG) e viabilidade (V) de sementes de $P$. setacea com umidade de $3,7 \%$, tratadas com ácido giberélico (GA3), ou não (testemunha - Test.), armazenadas em temperaturas de $4,-20$ e $-196{ }^{\circ} \mathrm{C}$.

\begin{tabular}{|c|c|c|c|c|c|c|c|c|c|}
\hline \multirow{4}{*}{$\begin{array}{l}\text { Armazenamento } \\
\text { (meses) }\end{array}$} & \multicolumn{9}{|c|}{ Temperatura de armazenamento } \\
\hline & \multicolumn{3}{|c|}{$4^{\circ} \mathrm{C}$} & \multicolumn{3}{|c|}{$-20^{\circ} \mathrm{C}$} & \multicolumn{3}{|c|}{$-196^{\circ} \mathrm{C}$} \\
\hline & \multicolumn{2}{|c|}{ Germinação (\%) } & \multirow{2}{*}{$\mathrm{V}(\%)$} & \multicolumn{2}{|c|}{ Germinação (\%) } & \multirow{2}{*}{$\mathrm{V}(\%)$} & \multicolumn{2}{|c|}{ Germinação (\%) } & \multirow{2}{*}{$\mathrm{V}(\%)$} \\
\hline & $\mathrm{GA}_{3}$ & Test. & & $\mathrm{GA}_{3}$ & Test. & & $\mathrm{GA}_{3}$ & Test. & \\
\hline 0 & $100 \mathrm{Aa}$ & $68 \mathrm{Ab}$ & $100 \mathrm{Aa}$ & $100 \mathrm{Aa}$ & $68 \mathrm{Ab}$ & $100 \mathrm{Aa}$ & $98 \mathrm{Aa}$ & $68 \mathrm{Ab}$ & $100 \mathrm{Aa}$ \\
\hline 1 & $80 \mathrm{Ba}$ & $20 \mathrm{Bc}$ & $100 \mathrm{Aa}$ & $56 \mathrm{Bb}$ & $28 \mathrm{Bc}$ & $100 \mathrm{Aa}$ & $92 \mathrm{Aa}$ & $40 \mathrm{Bb}$ & $98 \mathrm{Aa}$ \\
\hline 2 & $100 \mathrm{Aa}$ & $4 \mathrm{Cb}$ & $100 \mathrm{Aa}$ & $100 \mathrm{Aa}$ & $4 \mathrm{Cb}$ & $100 \mathrm{Aa}$ & $92 \mathrm{Aa}$ & $4 \mathrm{Cb}$ & $95 \mathrm{Aa}$ \\
\hline 3 & $100 \mathrm{Aa}$ & $8 \mathrm{Cb}$ & $100 \mathrm{Aa}$ & $100 \mathrm{Aa}$ & $4 \mathrm{Cb}$ & $100 \mathrm{Aa}$ & $98 \mathrm{Aa}$ & $4 \mathrm{Cb}$ & $100 \mathrm{Aa}$ \\
\hline 5 & $60 \mathrm{Cb}$ & $3 \mathrm{Dd}$ & $65 \mathrm{Bb}$ & $93 \mathrm{Aa}$ & $23 \mathrm{Bc}$ & $91 \mathrm{Aa}$ & $90 \mathrm{Aa}$ & $12 \mathrm{Bc}$ & $99 \mathrm{Aa}$ \\
\hline 6 & $3 \mathrm{Db}$ & $3 \mathrm{Db}$ & $51 \mathrm{Cb}$ & $15 \mathrm{Ca}$ & $5 \mathrm{Cb}$ & $75 \mathrm{Ba}$ & $15 \mathrm{Ba}$ & $5 \mathrm{Cb}$ & $75 \mathrm{Ba}$ \\
\hline 8 & $3 \mathrm{Db}$ & $0 \mathrm{Db}$ & $35 \mathrm{Cb}$ & $15 \mathrm{Ca}$ & $0 \mathrm{Cb}$ & $70 \mathrm{Ba}$ & $15 \mathrm{Ba}$ & $5 \mathrm{Cb}$ & $75 \mathrm{Ba}$ \\
\hline
\end{tabular}

Médias seguidas pela mesma letra minúscula na linha e maiúscula na coluna, não diferem estatísticamente. (Teste Tukey, p $\leq 0,05$ ).

A maioria dos modelos propostos para estimar germinação e dormência baseia-se em espécies de clima temperado. Para espécies de clima tropical, com clima úmido, o significado ecológico das alterações no comportamento germinativo durante $\mathrm{o}$ armazenamento em condições de baixa umidade é difícil de ser compreendido (Probert, 2001). Em condições naturais, no campo, as sementes de espécies de maracujá silvestres germinam sob alta temperatura, ou seja, durante os meses mais quentes do ano. Dessa forma, durante os meses mais frios e secos as sementes apresentam-se dormentes, iniciando a germinação com o aumento da temperatura. Assim, esse comportamento ecológico poderia explicar a indução de dormência em condição de baixa temperatura e reduzido conteúdo de umidade das sementes, que correspondem às condições de conservação a longo prazo.

Os resultados aqui obtidos mostram que, até o quinto mês de armazenamento, as sementes ainda apresentavam viabilidade elevada, mas, sem o tratamento com $\mathrm{GA}_{3}$, foi muito baixo. A amostra inicial de sementes e as armazenadas até o terceiro mês apresentaram freqüência considerável de sementes dormentes. Contudo, essa dormência foi superada pelo tratamento com ácido giberélico, devido à sua ação na indução da síntese e atividade de enzimas hidrolíticas que enfraquecem os tecidos do endosperma e da testa, e auxiliam a expansão do embrião (Bewley e Black, 1994). Porém, após o sexto mês, apesar da viabilidade das sementes permanecer relativamente elevada, o tratamento com ácido giberélico mostra-se ineficiente em superar a dormência. Finkelstein et al. (2008) apontaram que o acúmulo de giberelinas está associado com a superação da dormência; porém, em sementes de Arabidopsis em dormência profunda, o tratamento com ácido giberélico por si só não foi capaz de estimular a germinação. De forma geral, teoricamente, sementes superam a dormência quando submetidas à estratificação, ou seja, quando são expostas a baixas temperaturas. Porém, a literatura apresenta referências destacando que baixas temperaturas de armazenamento induzem a dormência. Jones et al. (1998) relataram que sementes de Picea sitchensis quando desidratadas até atingir grau de umidade próximo a $6 \%$ e armazenadas a $4{ }^{\circ} \mathrm{C}$ apresentaram-se dormentes. Banovetz e Scheiner (1994) detectaram que sementes de Coreopsis lanceolata apresentaram dormência secundária induzida pelo armazenamento a $5{ }^{\circ} \mathrm{C}$. Também, Ellery (2002) verificou que baixas temperaturas e potencial hídrico de $-1,5$ $\mathrm{MPa}$ induzem a dormência secundária em Arctotheca calendula, sendo que o ciclo de dormência das sementes desta espécie extremamente dependente da temperatura, variável entre as estações do ano. Hirano et al. (2009) também observaram que sementes de Phaius tankervilleae (Orchidaceae) com 5\% de umidade e armazenadas a $4{ }^{\circ} \mathrm{C}$ por 6 meses apresentaram baixa porcentagem de germinação, apesar de mostrarem-se viáveis pelo teste de tetrazólio. 
A avaliação realizada no oitavo mês de armazenamento mostrou que as sementes armazenadas a 4 e $-20{ }^{\circ} \mathrm{C}$ não tratadas com ácido giberélico, em quaisquer das temperaturas testadas, não germinaram. e quando tratadas, com $\mathrm{GA}_{3}$ apresentaram germinação muito baixa (3 a 15\%, respectivamente).

Os dados de avaliação da viabilidade pelo teste de tetrazólio mostraram que as temperaturas de armazenamento de -20 e $-196{ }^{\circ} \mathrm{C}$ foram mais eficientes para conservar a viabilidade das sementes por período prolongado, em relação à temperatura de $4{ }^{\circ} \mathrm{C}$. Até o terceiro mês de armazenamento, não foram detectadas diferenças significativas entre os efeitos de temperaturas de armazenamento sobre a viabilidade.

Assim, a dormência de sementes de $P$. setacea submetidas à conservação em longo prazo é uma ocorrência relevante, que deve ser considerada no estabelecimento de estratégias para a conservação de sementes em bancos de germoplasma. Assim, uma vez que a ocorrência de dormência e sua profundidade podem ser alteradas em condições de conservação em longo prazo (Ellis et al., 1993; Pérez-García et al., 2007), no caso de espécies não domesticadas e até mesmo para algumas cultivadas, é recomendável a utilização conjunta de testes de germinação e de viabilidade (TZ), de forma a permitir a obtenção de melhores estimativas sobre o desempenho de sementes conservadas.

\section{CONCLUSÕES}

Sementes de $P$. setacea são tolerantes à dessecação até níveis próximos de $4 \%$ de água.

Baixas umidades e temperatura de armazenamento induzem as sementes de $P$. setacea à dormência.

A longevidade das sementes de $P$. setacea é maior quando armazenadas em temperaturas subzero.

\section{REFERÊNCIAS}

ALBRECHT, M.; MCCARTHY, B. Effects of storage on seed dormancy and survivorship in black cohosh (Actaea racemosa L.) and goldenseal (Hydrastis canadensis L.). Seed Science and Technology, v.35, n.2, p.414-422, 2007.

BARROS, D.I. Tecnologia de sementes de mangaba (Hancornia speciosa Gomes). 2006. 89f. Tese (Doutorado em Agronomia na área de concentração de Sementes) Universidade Federal de Paraiba, 2006.
BANOVETZ, S.J.; SCHEINER, S.M. Secondary seed dormancy in Coreopsis lanceolata. American Midland Naturalist, v.131, n.1, p.75-83, 1994.

BERNACCI, L.C. ; MELETTI, L.M.M.; SCOTT, M.D.S. Maracujá-doce: o autor, a obra e a data da publicação de Passiflora alata (Passifloraceae). Revista Brasileira de Fruticultura, v.25, n.2, p.355-356, 2003.

BEWLEY, J.D.; BLACK, M. Seeds: physiology of development and germination. 2.ed. New York: Plenum Press, 1994.

BRAGA, M.F.; JUNQUEIRA, N.T.V.. Uso potencial de outras espécies do gênero Passiflora. Informe Agropecuario, v.21, n. 206, p.72-75, 2000.

BRAGA, M.F.; JUNQUEIRA, N.T.V.; FALEIRO, F.G.; BELLON, G.; JUNQUEIRA, K.P. Maracujá-doce: melhoramento genético e germoplasma. In: FALEIRO, F.G.; JUNQUEIRA, N.T.V.; BRAGA, M.F. Maracujá: germoplasma e melhoramento genético. Planaltina, DF: Embrapa Cerrados 2005. p.601-617.

BRASIL. Ministério da Agricultura e Reforma Agrária. SecretariaNacionaldeDefesa Agropecuária. Departamento Nacional de Produção Vegetal. Coordenação de Laboratório Vegetal. Regras para Análise de Sementes. Brasília, DF, 1992. 365p.

DELANOY, M.; VAN DAMMEA, P.; SCHELDEMAN, X.; BELTRAN, J. Germination of Passiflora mollissima (Kunth) LH Bailey, Passiflora tricuspis Mast. and Passiflora nov sp. seeds. Scientia Horticulturae, v.110, n.2, p.198-203, 2006.

ELLERY, A.J. Embryo dormancy responses to temperature in capeweed (Arctotheca calendula) seeds. Seed Science Research, v.12, p.181-191, 2002.

ELLIS, R. T.; HONG. T.D.; ROBERTS, E.H. Handbook of seed technology for genebanks, Roma: International Board for Plant Genetic Resources, IBPGR. 1985.

ELLIS, R.H.; HONG, T.D.; MARTIN, M.C.; PÉREZGARCÍA, F.; GÓMEZ-CAMPO, C. The long-term storage of seeds of seventeen crucifers at very low moisture contents. Plant Varieties and Seeds v.6, p.75-81, 1993.

FINKELSTEIN, R.; REEVES, W.; ARIIZUMI, T.; STEBER, C. Molecular Aspects of Seed Dormancy. Annual Review of Plant Biology, v.59, p.387-415, 2008 .

HIRANO, T.; GODO, T.; MIYOSHI, K.; ISHIKAWA, K.; ISHIKAWA, M.; MII, M. Cryopreservation and lowtemperature storage of seeds of Phaius tankervilleae. 
Plant Biotechnology, v.3, p.103-109, 2009.

IBGE. Instituto Brasileiro de Geografia e Estatística. Consulta ao site: $<$ http://www.sidra.ibge.gov.br/bda/ tabela/protabl.asp? $\mathrm{c}=1613 \& \mathrm{z}=\mathrm{t} \& \mathrm{o}=11 \& \mathrm{i}=\mathrm{P}>. \quad$ Acesso em: 26 jun. 2009.

JONES, S.K.; GOSLING, P.G.; ELLIS, R.H. Reimposition of conditional dormancy during air-dry storage of prechilled Sitka spruce seeds. Seed Science Research, v.8, p.113-122, 1998.

JUNQUEIRA, N.T.V.; BRAGA, M.F.; FALEIRO, F.G.; PEIXOTO, J.R.; BERNACCI, L.C. Potencial de espécies silvestres de maracujazeiro como fonte de resistência a doenças. In: FALEIRO, F.G., JUNQUEIRA, N.T.V. e BRAGA, M.F. Maracujá: germoplasma e melhoramento genético. Planaltina, DF: Embrapa Cerrados, p.81-108. 2005 .

MEZZALIRA, E.J.; PIVA, A.L.; MENDES, A.S.; PAULUS, D.; WAGNER JÚNIOR, A.; NAVA, G.A. Emergência de plântulas de maracujazeiro (Passiflora edulis Simsf. flavicarpa Deg.) em resposta ao ambiente e ao tempo de armazenamento de sementes. In: SEMINÁRIO: SISTEMAS DE PRODUÇÃO AGROPECUÁRIAAGRONOMIA, 3., UTFPR. Disponível em $<$ http:// web.dv.utfpr.edu.br/seer/index.php/SSPA/article/ view/123/20>. Acesso em: 22 nov. 2009.

OLIVEIRA, J.C.; RUGGIERO, C. Espécies de maracujá com potencial agronômico. In: FALEIRO, F.G.; JUNQUEIRA, N.T.V.; BRAGA, M.F. (Ed.). Maracujá: germoplasma e melhoramento genético. Planaltina: Embrapa Cerrados, 2005, cap. 6, p.143-158.

OLIVEIRA, J.C.; NAKAMURA, K.; MAURO, A.O.; CUNHA, M.A.P. Aspectos gerais do melhoramento do maracujazeiro. In: SÃO JOSÉ, A.R. Maracujá: produção e mercado. Vitória da Conquista: DFZ-UESB, p.27-37. 1994.
PEIXOTO, M. Problemas e perspectivas do maracujá ornamental. In: FALEIRO, F.G.; JUNQUEIRA, N.T.V.; BRAGA, M.F. (Ed.). Maracujá: germoplasma e melhoramento genético. Planaltina: Embrapa Cerrados, 2005 , cap. 18 , p. 457-463.

PÉREZ-GARCÍA, F. et al. High viability recorded in ultra-dry seeds of 37 species of Brassicaceae after almost 40 years of storage. Seed Science and Technology, v.35, n.1, p.143-153, 2007.

PRITCHARD, H. Classification of seed storage 'types' for ex situ conservation in relation to temperature and moisture. In: GUERRANT Jr., E.O.; HAVENS, K.; MAUNDER, M. (Ed.). Ex situ plant conservation: supporting species survival in the wild. Washington: Island Press, 2004. p.139-161.

PROBERT, R.J. The role of temperature in the regulation of seed dormancy and germination. In: Fenner, $M$. (Ed.) Seeds. The Ecology of Regeneration in Plant Communities, 2.ed. CABI, Wallingford, Reino Unido. 2001, cap. 11, p.261-292.

RUIZ, M. MARTÍN, I.; de La CUADRA, C. Cereal seed viability after 10 years of storage in active and base germplasm collections. Field Crops Research, v.64, n.3, p.229-236, 1999.

SOUZA, J.S.I.; MELETTI, L.M.M. Maracujá: espécies, variedades e cultivo. Piracicaba: FEALQ. 1997, 179p.

VITTA, F.A.; BERNACCI, L.C. A new species and two overlooked species of Passiflora (Passifloraceae) from Brazil. Brittonia, v.56, p.89-95, 2004.

WOOD, C.B.; PRITCHARD, H.W.; AMRITPHALE, D. Desiccation-induced dormancy in papaya (Carica papaya L.) seeds is alleviated by heat shock. Seed Science Research, v.10, n.2, p.135-145, 2000. 